\title{
Leg Weakness Caused by Bilateral Piriformis Syndrome: A Case Report
}

\author{
Hee Bong Moon, MD, Ki Yeun Nam, MD, Bum Sun Kwon, MD, Jin Woo Park, MD, \\ Gi Hyeong Ryu, MD, Ho Jun Lee, MD, Chang Jae Kim, MD
}

Department of Physical Medicine and Rehabilitation, Dongguk University College of Medicine, Goyang, Korea

\begin{abstract}
Piriformis syndrome (PS) is an uncommon neuromuscular disorder caused by the piriformis muscle (PM) compressing the sciatic nerve (SN). The main symptom of PS is sciatica, which worsens with certain triggering conditions. Because the pathophysiology is poorly understood, there are no definite diagnostic and therapeutic choices for PS. This case report presents a young woman who mainly complained of bilateral leg weakness. Electromyography revealed bilateral sciatic neuropathy and magnetic resonance imaging confirmed structural lesions causing entrapment of the bilateral SNs. After a laborious diagnosis of bilateral PS, she underwent PM releasing surgery. Few PS cases present with bilateral symptoms and leg weakness. Therefore, in such cases, a high level of suspicion is necessary for accurate and prompt diagnosis and treatment.
\end{abstract}

Keywords Piriformis muscle syndrome, Bilateral, Muscle weakness

\section{INTRODUCTION}

Piriformis syndrome (PS) is an uncommon neuromuscular disorder caused by sciatic nerve (SN) compression at the infra-piriformis canal by piriformis muscle (PM) abnormalities including spasm, edema, and contracture [1-3]. The main symptom of PS is sciatica of the buttocks along the pathway of the SN down to the lower thighs and legs; this condition worsens with certain triggering positions [1-3]. The pathophysiology is poorly understood.

Received October 17, 2014; Accepted April 9, 2015

Corresponding author: Ki Yeun Nam

Departments of Physical Medicine and Rehabilitation, Dongguk University College of Medicine, 27 Dongguk-ro, Ilsandong-gu, Goyang 10326, Korea Tel: +82-31-961-7487, Fax: +82-31-961-7488, E-mail: rus198@hanmail.net

(c) This is an open-access article distributed under the terms of the Creative Commons Attribution Non-Commercial License (http://creativecommons. org/licenses/by-nc/4.0) which permits unrestricted noncommercial use, distribution, and reproduction in any medium, provided the original work is properly cited.

Copyright () 2015 by Korean Academy of Rehabilitation Medicine
There are no gold standard diagnostic and therapeutic choices for PS [1,2].

PS cases where patients present with bilateral symptoms and complain mainly of leg weakness have not been reported before.

\section{CASE REPORT}

A 32-year-old female was admitted to our neurology department six years ago with left sciatica, back pain and mild left leg weakness. With regard to weakness, only a slight decrease in left ankle dorsiflexion strength was present. The central to right disc bulge with right first sacral (S1) nerve root abutting and left S1 nerve root swelling were detected on magnetic resonance imaging (MRI) (Fig. 1). Left L5, S1 radiculopathy was suspected on electromyography (EMG). These findings led to the diagnosis of herniated intervertebral disc disease (HIVD) and managed with medication. 

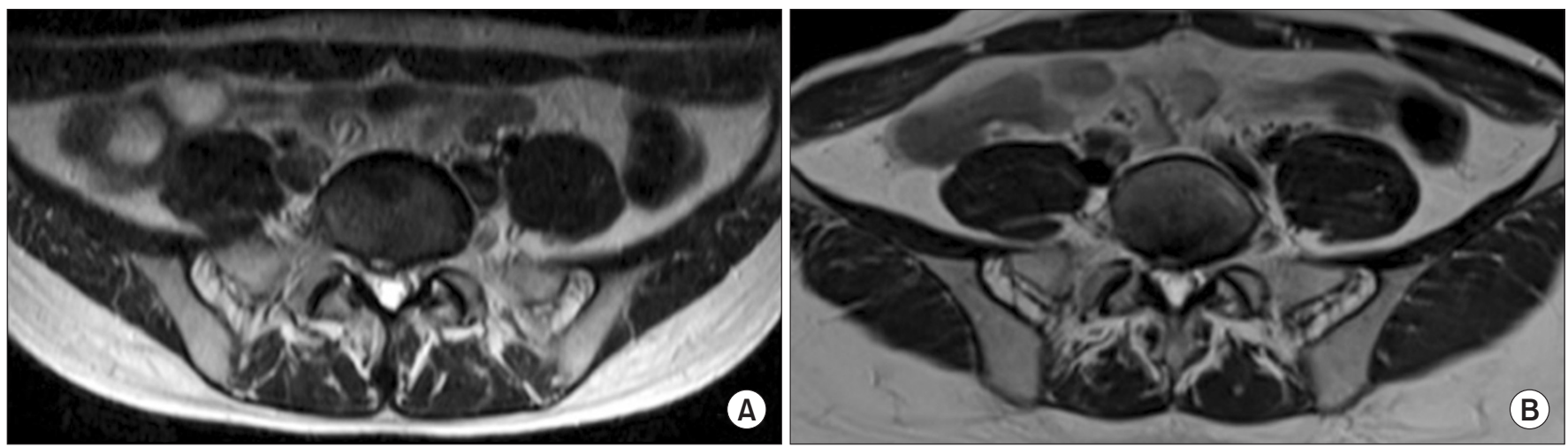

Fig. 1. Axial T2-weighted images of the spine MRI. (A) Central to right disc bulging and left S1 nerve root swelling observed in 2008. (B) Improved disc bulging and left S1 nerve root swelling is not observed anymore in 2014.
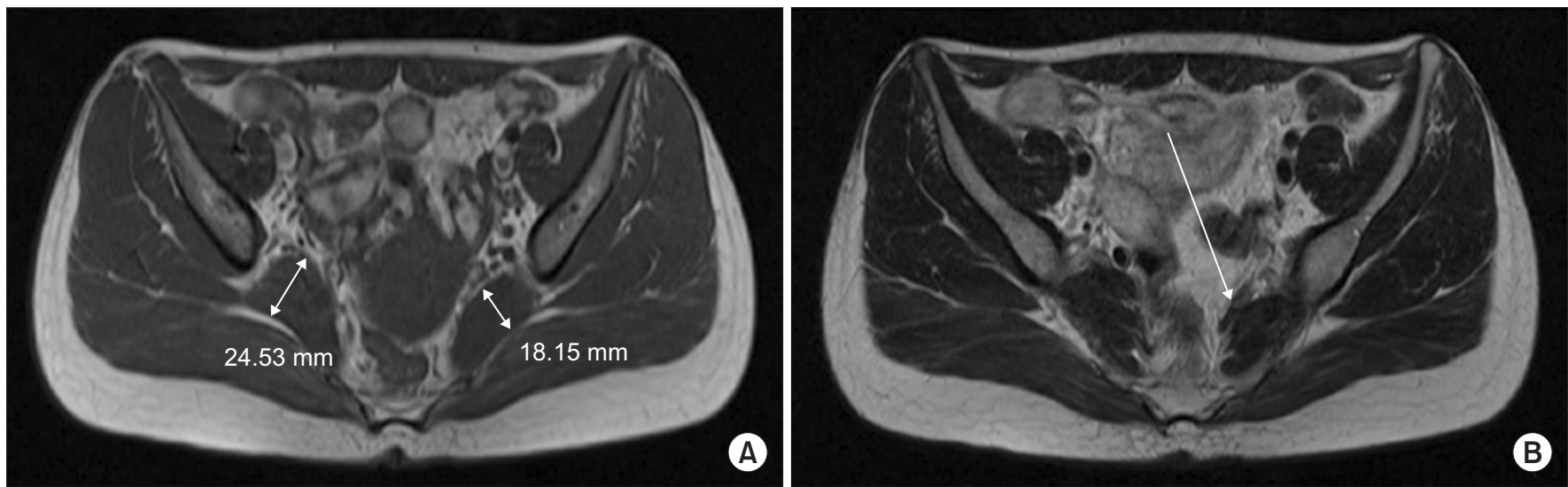

Fig. 2. Images of the first hip MRI whose reading was noted as normal. In fact, (A) axial T1-weighted image of hip MRI shows asymmetric enlargement of right piriformis muscle. (B) Axial T2-weighted image shows dark signal band-like structure at anterior to left piriformis muscle.

After one year, she complained of insidious left foot drop without any preceding events and revisited our neurology department. Left ankle dorsiflexion strength was grade 4 on the manual muscle test (MMT) with persistent sciatica. Special tests for PS such as piriformis sign, flexion-adduction-internal rotation test were negative. Left sciatic neuropathy was suggested from EMG. A hip MRI was performed and the radiologist noted no evidence of abnormality at both SNs (Fig. 2). This time she was diagnosed as left sciatic neuropathy and was prescribed of self-exercise with medication.

She visited our clinic on April 2014, complaining of left sciatica with leg weakness, which has been sustained for six years along with a newly developed right sciatica with leg weakness for one month. In MMT (right/left), ankle dorsiflexion $(4 / 2+)$, ankle plantar flexion $(4 / 3+)$, and big- toe extension $(3 / 2+)$ were evaluated. In the isokinetic test, left ankle dorsiflexor was only $10 \%$ of the right side. Special tests for PS were negative and steppage gait was observed. Routine laboratory exams were normal. For the recurrent peripheral neuropathic symptoms, a laboratory exam of peripheral myelin protein-22 was done suspecting possible hereditary neuropathy with liability to pressure palsies, but showed negative result. Bilateral sciatic neuropathy was diagnosed with EMG (Tables 1, 2). In second hip MRI, the size of right PM was significantly increased compared to previous exam [4] and a band-like structure at the anterior to left PM was compressing the left SN (Fig. 3). Based on these findings she was finally diagnosed with bilateral PS.

A PM releasing operation of the left side was done first. The PM tendon totally dissected at the greater trochanter 
Table 1. Result of the nerve conduction studies

\begin{tabular}{|c|c|c|c|c|c|c|c|c|}
\hline \multirow{2}{*}{ Nerve } & \multirow{2}{*}{$\begin{array}{c}\text { Stimulation } \\
\text { site }\end{array}$} & \multirow{2}{*}{$\begin{array}{c}\text { Recording } \\
\text { site }\end{array}$} & \multicolumn{2}{|c|}{ Amplitude } & \multicolumn{2}{|c|}{ Latency (ms) } & \multicolumn{2}{|c|}{$\mathrm{CV}(\mathrm{m} / \mathrm{s})$} \\
\hline & & & Rt & Lt & Rt & $\mathbf{L t}$ & $\mathbf{R t}$ & $\mathbf{L t}$ \\
\hline \multirow[t]{2}{*}{ Peroneal (M) } & Ankle & EDB & 4.3 & 2.2 & 4.65 & 4.90 & - & - \\
\hline & Below fibular & EDB & 4.2 & 0.9 & 9.50 & 11.30 & 55.7 & 40.6 \\
\hline \multirow[t]{2}{*}{ Tibial (M) } & Ankle & AHB & 16.8 & 24.8 & 3.25 & 4.20 & - & - \\
\hline & Popliteal fossa & AHB & 14.0 & 19.4 & 9.45 & 11.85 & 51.6 & 44.4 \\
\hline Peroneal (S) & Lateral leg & Foot & 13.8 & 8.4 & 2.40 & 2.40 & - & - \\
\hline Sural (S) & Calf & Lateral malleolus & 37.5 & 38.3 & 2.05 & 2.3 & - & - \\
\hline
\end{tabular}

All motor and sensory latencies are onset latencies.

Amplitudes are measured in millivolt ( $\mathrm{mV}$, motor) and in microvolt ( $\mu \mathrm{V}$, sensory).

M, motor study; S, sensory study; CV, conduction velocity; Rt, right; Lt, left; EDB, extensor digitorum brevis; AHB, adductor halluces brevis.

Table 2. Needle electromyography studies

\begin{tabular}{|c|c|c|c|c|c|c|c|}
\hline & \multicolumn{3}{|c|}{ Spontaneous activity } & \multicolumn{4}{|c|}{ Motor unit action potential } \\
\hline & IA & Fib & PSW & $\operatorname{Amp}(\boldsymbol{\mu V})$ & Dur (ms) & PPP & Recruitment pattern \\
\hline Rt tibialis anterior & $\mathrm{N}$ & $1+$ & $2+$ & Inc & $\mathrm{N}$ & + & Reduced \\
\hline Rt gastrocnemius (medial head) & $\mathrm{N}$ & $1+$ & $2+$ & Inc & $\mathrm{N}$ & + & Reduced \\
\hline Rt peroneus longus & $\mathrm{N}$ & $2+$ & $2+$ & $\mathrm{N}$ & $\mathrm{N}$ & + & Reduced to complete \\
\hline Rt vastus medialis & $\mathrm{N}$ & $\mathrm{N}$ & $\mathrm{N}$ & $\mathrm{N}$ & $\mathrm{N}$ & $\mathrm{N}$ & Complete \\
\hline Rt biceps femoris (short head) & $\mathrm{N}$ & $1+$ & $1+$ & $\mathrm{N}$ & $\mathrm{N}$ & $\mathrm{N}$ & Reduced to complete \\
\hline Rt semimembranosus & $\mathrm{N}$ & $1+$ & $1+$ & $\mathrm{N}$ & $\mathrm{N}$ & $\mathrm{N}$ & Reduced to complete \\
\hline Rt gluteus maximus & $\mathrm{N}$ & $\mathrm{N}$ & $\mathrm{N}$ & $\mathrm{N}$ & $\mathrm{N}$ & $\mathrm{N}$ & Complete \\
\hline Rt gluteus medius & $\mathrm{N}$ & $\mathrm{N}$ & $\mathrm{N}$ & $\mathrm{N}$ & $\mathrm{N}$ & $\mathrm{N}$ & Complete \\
\hline Rt adductor longus & $\mathrm{N}$ & $\mathrm{N}$ & $\mathrm{N}$ & $\mathrm{N}$ & $\mathrm{N}$ & $\mathrm{N}$ & Complete \\
\hline Rt L5 paraspinalis & $\mathrm{N}$ & $\mathrm{N}$ & $\mathrm{N}$ & - & - & - & - \\
\hline Rt S1 paraspinalis & $\mathrm{N}$ & $\mathrm{N}$ & $\mathrm{N}$ & - & - & - & - \\
\hline Lt tibialis anterior & $\mathrm{N}$ & $4+$ & $4+$ & $\mathrm{N}$ & $\mathrm{N}$ & $\mathrm{N}$ & Single to reduced \\
\hline Lt gastrocnemius (medial head) & $\mathrm{N}$ & $3+$ & $3+$ & $\mathrm{N}$ & $\mathrm{N}$ & $\mathrm{N}$ & Single \\
\hline Lt peroneus longus & $\mathrm{N}$ & $3+$ & $3+$ & $\mathrm{N}$ & $\mathrm{N}$ & + & Single to reduced \\
\hline Lt biceps femoris (short head) & $\mathrm{N}$ & $2+$ & $2+$ & $\mathrm{N}$ & $\mathrm{N}$ & $\mathrm{N}$ & Reduced to complete \\
\hline Lt semimembranosus & $\mathrm{N}$ & $2+$ & $2+$ & $\mathrm{N}$ & $\mathrm{N}$ & $\mathrm{N}$ & Reduced to complete \\
\hline Lt gluteus maximus & $\mathrm{N}$ & $\mathrm{N}$ & $\mathrm{N}$ & $\mathrm{N}$ & $\mathrm{N}$ & $\mathrm{N}$ & Complete \\
\hline Lt gluteus medius & $\mathrm{N}$ & $\mathrm{N}$ & $\mathrm{N}$ & $\mathrm{N}$ & $\mathrm{N}$ & $\mathrm{N}$ & Complete \\
\hline Lt L5 paraspinalis & $\mathrm{N}$ & $\mathrm{N}$ & $\mathrm{N}$ & - & - & - & - \\
\hline Lt S1 paraspinalis & $\mathrm{N}$ & $\mathrm{N}$ & $\mathrm{N}$ & - & - & - & - \\
\hline
\end{tabular}

IA, insertional activity; Fib, fibrillation; PSW, positive sharp wave; Amp, amplitude; Dur, duration; PPP, polyphasic pattern; N, normal; Inc, increased.

and an intra-operatively thickened PM was observed. A month later, operation of the right side was executed with the same operative findings. After the surgery, sciatica improved and showed a visual analog scale from 3 to 0 .

The subject's rehabilitation program began with streng- thening exercises and gait training with hinged type ankle-foot-orthosis (AFO) on the left. After the surgery, an involuntary internal rotation of hip developed, so we strengthened her hip external-rotators for correction. Two months after the surgery, in-toeing gait was persis- 

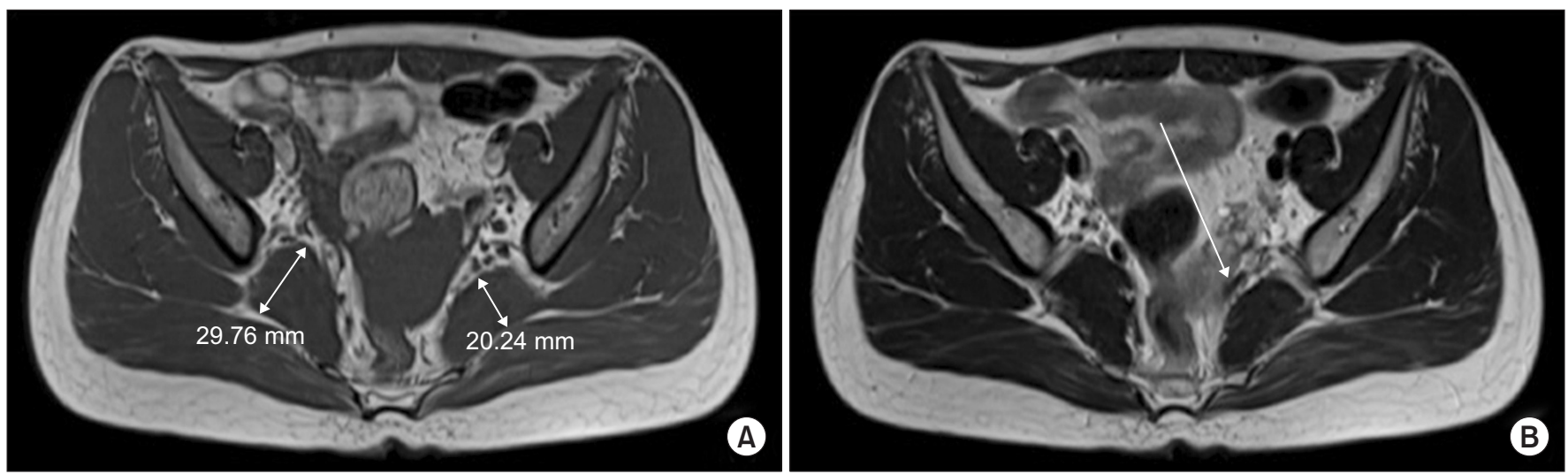

Fig. 3. Recent hip MRI images taken in 2014. (A) Axial T1-weighted image shows asymmetric enlargement of right piriformis muscle, which increased in size, compared with previous exam. (B) Axial T2-weighted image shows dark signal band-like structure at anterior to left piriformis muscle, reducing space around the left sciatic nerve tract.

tent and AFO was kept on. However, follow-up isokinetic tests revealed her ankle dorsiflexion improved 3.4 times on the right side and 19 times on the left side compared to the tests before operations. Side to side difference also decreased from $90 \%$ to $44 \%$ [5].

\section{DISCUSSION}

Bilateral PS is very rare and few cases have been reported. In most cases, predisposing factors such as trauma, operation history, and underlying disease were noted [6]. However, in our case, the patient was young and did not have any of these predisposing factors. So this is the first case of bilateral PS, with two different causes, enlarged PM and a band-like PM, presenting simultaneously.

At initial visit, her symptoms suggested HIVD. The EMG study showed abnormal spontaneous activity on left tibialis anterior and gastrocnemius. Central to right disc bulging between L5 and S1 and left S1 nerve root swelling were detected on MRI but during the EMG study, and proximal muscles of L5, S1 myotome showed no abnormal findings. Therefore, there was discrepancy between radiologic and electromyographic findings. On her third visit, symptoms were aggravated despite second spine MRI showing improvement of root swelling. These findings suggest the symptoms were a result of other causes rather than HIVD. Follow-up EMG results indicated sciatic neuropathy not radiculopathy, therefore it is presumable that her initial diagnosis should have been both HIVD and PS. Nevertheless, her six years of long-standing symptoms including leg weakness favored PS. In first hip
MRI, no abnormality of SN was assessed at the reading. However, a band like lesion, thought to be the cause of left PS, also was detected in the first hip MRI (Fig. 2B). This delayed accurate diagnosis.

Considering that her chief complaint was bilateral leg weakness rather than sciatica and that the patient was relatively young, we needed a longstanding treatment plan. Total dissection of left PM was executed and her sciatica significantly improved. The subject underwent the second operation for the other side as well. Both operations left minimal scaring. However, the operations possibly made tiny surrounding structures, including SN, hard to discern. Moreover, considering her postsurgical in-toeing gait, we wonder if botulinum toxin injection or partial dissection of PM preceding surgery may have been better choice [7].

Common complications of PM release surgery include hematoma and infection [8], and this in-toeing gait is the first reported complication. As gluteus maximus is a powerful external rotator of the hip [9], in-toeing was not predicted before the surgery. Nevertheless, in our case, a thickened PM was confirmed in both MRI and the operation field. We presume that a portion of her PM on hip external rotation action may have been much greater than in general people. Therefore, the PM releasing could have caused the in-toeing gait. We failed to find any predisposing factors inducing her PM enlargement.

In conclusion, as PS is very rare disease and is hard to distinguish from radiculopathy, a high index of suspicion is mandatory for accurate diagnosis. When proximal hip girdle muscles and paraspinal muscles are normal in 
EMG [10], an MRI exam should be taken to investigate entire pathway of SN from lumbosacral root outlet until it passes the PM. All measures should be taken to prevent any motor deficit progression as presented in this case.

\section{CONFLICT OF INTEREST}

No potential conflict of interest relevant to this article was reported.

\section{REFERENCES}

1. Hopayian K, Song F, Riera R, Sambandan S. The clinical features of the piriformis syndrome: a systematic review. Eur Spine J 2010;19:2095-109.

2. Michel F, Decavel P, Toussirot E, Tatu L, Aleton E, Monnier G, et al. Piriformis muscle syndrome: diagnostic criteria and treatment of a monocentric series of 250 patients. Ann Phys Rehabil Med 2013;56:37183.

3. Michel F, Decavel P, Toussirot E, Tatu L, Aleton E, Monnier G, et al. The piriformis muscle syndrome: an exploration of anatomical context, pathophysiological hypotheses and diagnostic criteria. Ann Phys Rehabil Med 2013;56:300-11.
4. Rossi P, Cardinali P, Serrao M, Parisi L, Bianco F, De Bac S. Magnetic resonance imaging findings in piriformis syndrome: a case report. Arch Phys Med Rehabil 2001;82:519-21.

5. Woodson C, Bandy WD, Curis D, Baldwin D. Relationship of isokinetic peak torque with work and power for ankle plantar flexion and dorsiflexion. J Orthop Sports Phys Ther 1995;22:113-5.

6. Uchio Y, Nishikawa U, Ochi M, Shu N, Takata K. Bilateral piriformis syndrome after total hip arthroplasty. Arch Orthop Trauma Surg 1998;117:177-9.

7. Al-Al-Shaikh M, Michel F, Parratte B, Kastler B, Vidal C, Aubry S. An MRI evaluation of changes in piriformis muscle morphology induced by botulinum toxin injections in the treatment of piriformis syndrome. Diagn Interv Imaging 2015;96:37-43.

8. Benson ER, Schutzer SF. Posttraumatic piriformis syndrome: diagnosis and results of operative treatment. J Bone Joint Surg Am 1999;81:941-9.

9. Jenkins DB. Hollinshead's functional anatomy of the limbs and back. 9th ed. Philadelphia: Saunders; 2009. p. 294-306.

10. Dumitru D, Amato AA, Zwarts MJ. Electrodiagnostic medicine. 2nd ed. Philadelphia: Hanley \& Belfus; 2002. p. 713-76. 